\title{
NMR STUDY OF SOME ERYTHROMYCIN AGLYCONES. A CONFORMATIONAL AND CONFIGURATIONAL ANALYSIS
}

\author{
Paul V. Demarco \\ Department of Molecular Structure Research \\ The Lilly Research Laboratories \\ Indianapolis, Indiana 46206, U. S. A.
}

(Received for publication May 6, 1969)

\begin{abstract}
The proton magnetic resonance spectra of some erythromycin aglycones have been investigated at $100 \mathrm{MHz}$ in both deuteriochloroform and pyridine- $\mathrm{d}_{5}$ solvents. Utilizing information derived from pyridine solvent $\Delta$-values $(\Delta=$ $\delta \mathrm{CDCl}_{3}-\delta \mathrm{C}_{5} \mathrm{D}_{5} \mathrm{~N}$ ) and spin-spin coupling constants for vicinal protons, the preferred approximate conformations of these 14-membered lactone ring systems in solution have been shown to be the same in III, IV, V and VI and to closely approximate the conformation previously derived from $\mathrm{X}$-ray analysis for the aglycone ring in erythromycin A. The asymmetry at C-9 in dihydroaglycones IV, V and VI has been shown to be $S$ in V and VI and $R$ in IV. The utility of pyridine solvent shifts in the three-dimensional analysis of hydroxylic compounds is uniquely demonstrated in these polyhydroxy macrolides and emphasizes the potential of this technique for structure analysis.
\end{abstract}

Because of the considerable superimposition of resonance signals arising from protons and methyl groups situated on the sugar and aglycone rings in erythromycins $A$ and $B$, unambiguous signal assignment in the spectra of these antibiotics is both difficult and hazardous. As a starting point in the spectral analysis of these antibiotics, this studya) is directed to an investigation of several of the aglycones derived from erythromycins $\mathrm{A}$ and $\mathrm{B}$ and derivatives thereof, i.e., erythronolide $\mathrm{B}^{3)}$ (III), the
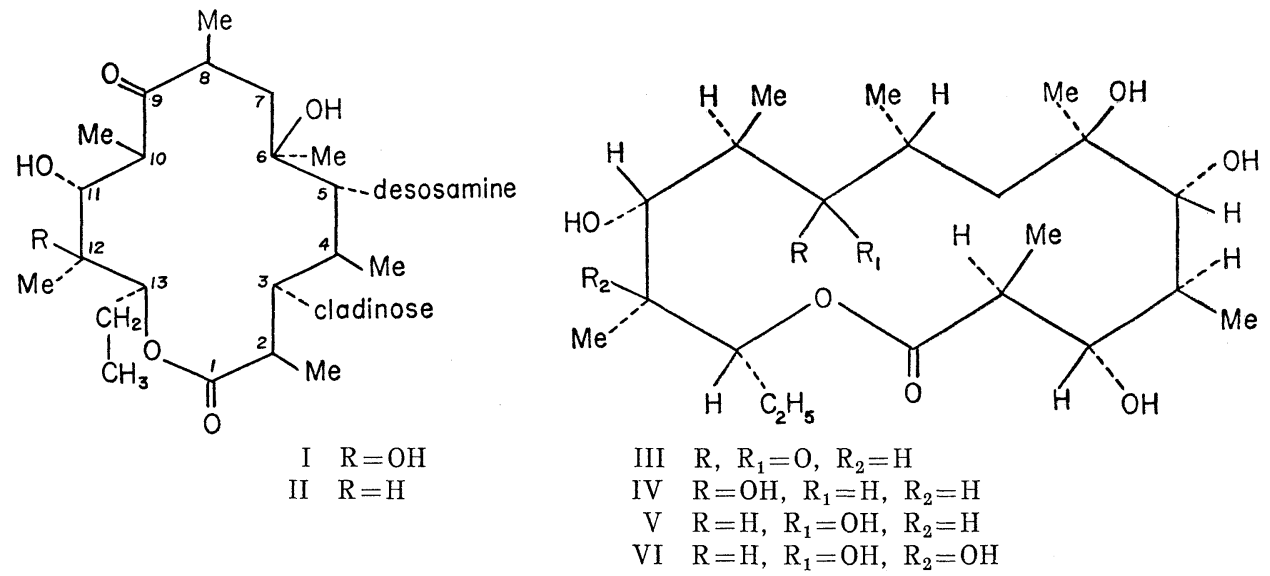

a) Preliminary nmr studies of these and related macrolides have been the subject of earlier communications (See References 1 and 2). 
two C-9 epimers of 9-dihydroerythronolide $\mathrm{B}^{4,5)}(\mathrm{IV} \text { and } \mathrm{V})^{\mathrm{b}, \mathrm{c})}$ and 9-dihydroerythronolide $\mathrm{A}^{6)}(\mathrm{VI})^{\mathrm{d})}$.

As an aid in the spectral analysis of compounds $I I I \sim V I$, pyridine- $d_{5}$ has been employed as solvent in addition to deuteriochloroform. The ability of pyridine to effect increased spectral simplification (relative to $\mathrm{CDCl}_{3}$ ) in the pmr spectra of polar molecules is well known and has been demonstrated on a number of previous occasions $^{7,8)}$. Additionally, since a number of empirical correlations have been established relating the chemical shift induced in pyridine (relative to chloroform) to specific structural features in the vicinity of a solute hydroxyl function ${ }^{8 \sim 13)}$ the measurement of pyridine $\Delta$-values $\left(\Delta=\delta \mathrm{CDCl}_{3}-\delta \mathrm{C}_{5} \mathrm{D}_{5} \mathrm{~N}\right)$ provides a potentially powerful method for investigating configurational and conformational relationships in the polyhydroxy aglycones presently under study.

Prior to preliminary reports of this work $^{1,2)}$, relative and absolute configurational assignments for the C-9 hydroxyl function in IV, V and VI were as yet unproven, although for the latter compuund (VI), previous studies had suggested, based on not entirely unambiguous results, that the configuration at G-9 was $S^{6,14)}$. A recent X-ray study ${ }^{14)}$, carried out by HARRIs et al., has defined the conformation of the aglycone ring in erythromycin A (I); and CeLmer has proposed a similar conformation for the macrolide ring in the related antibiotic oleandomycin ${ }^{15}$, based on a strain-free model in which non-bonded interactions between substituents are made minimal. However, since X-ray studies are carried out on the crystal; and as CELmer's proposed aglycone conformation had yet to be experimentally verified, it remained to be shown that this same conformation exists in solution.

\section{Results and Discussion}

The pmr spectra of compounds III, IV, V and VI, taken in both deuteriochloroform and pyridine $-\mathrm{d}_{5}$ solvents, are shown in Figs. 1 4 respectively. Inspection of these spectra reveals that, as predicted ${ }^{7,8)}$, peak separations for the various resonances are greater in pyridine- $d_{5}$ than in deuteriochloroform, especially in the methyl regions of these spectra. Thus, for greater clarity, shift assignment in this paper is discussed with reference to the pyridine- $d_{5}$ spectra only. The rationale employed in the first order analysis of the pyridine- $d_{5}$ spectra has been similarly applied to analysis of the deuteriochloroform spectra, although not discussed here, and final assignments for all pertinent signals in both solvents recorded in Table 1.

Shift Assignment of Aglycone Ring Protons and Methyl Groups

The most readily assigned signal in the spectra of these compounds is the $\mathrm{H}-13$

b) Compound IV (m. p. $189 \sim 190^{\circ}$ ) is one epimer obtained from sodium borohydride reduction of erythronolide $\mathrm{B}^{4)}$. The author is grateful to Dr. T. J. PERUN of Abbott Laboratories for generous samples of both the $9 \mathrm{R}-$ and $9 \mathrm{~S}$-epimers.

c) Compound V (m. p. $185 \sim 186^{\circ}$ ), the epimer of compound IV, was first obtained by sodium borohydride reduction of erythromycin B (II) followed by hydrolytic cleavage of the two sugar units $^{5}$. From comparison of their X-ray patterns, V was shown to be identical to a sample of the second epimer obtained from Abbott Laboratories from reduction of erythronolide $B$.

d) Compound VI, 9-dihydroerythronolide A, was obtained by sodium borohydride reduction of erythromycin A (I) followed by hydrolytic cleavage of the two sugar units ${ }^{6}$. 
Fig. 1. PMR spectrum of erythronolide B (III) in pyridine- $\mathrm{d}_{5}$ (A) and deuteriochloroform (B)
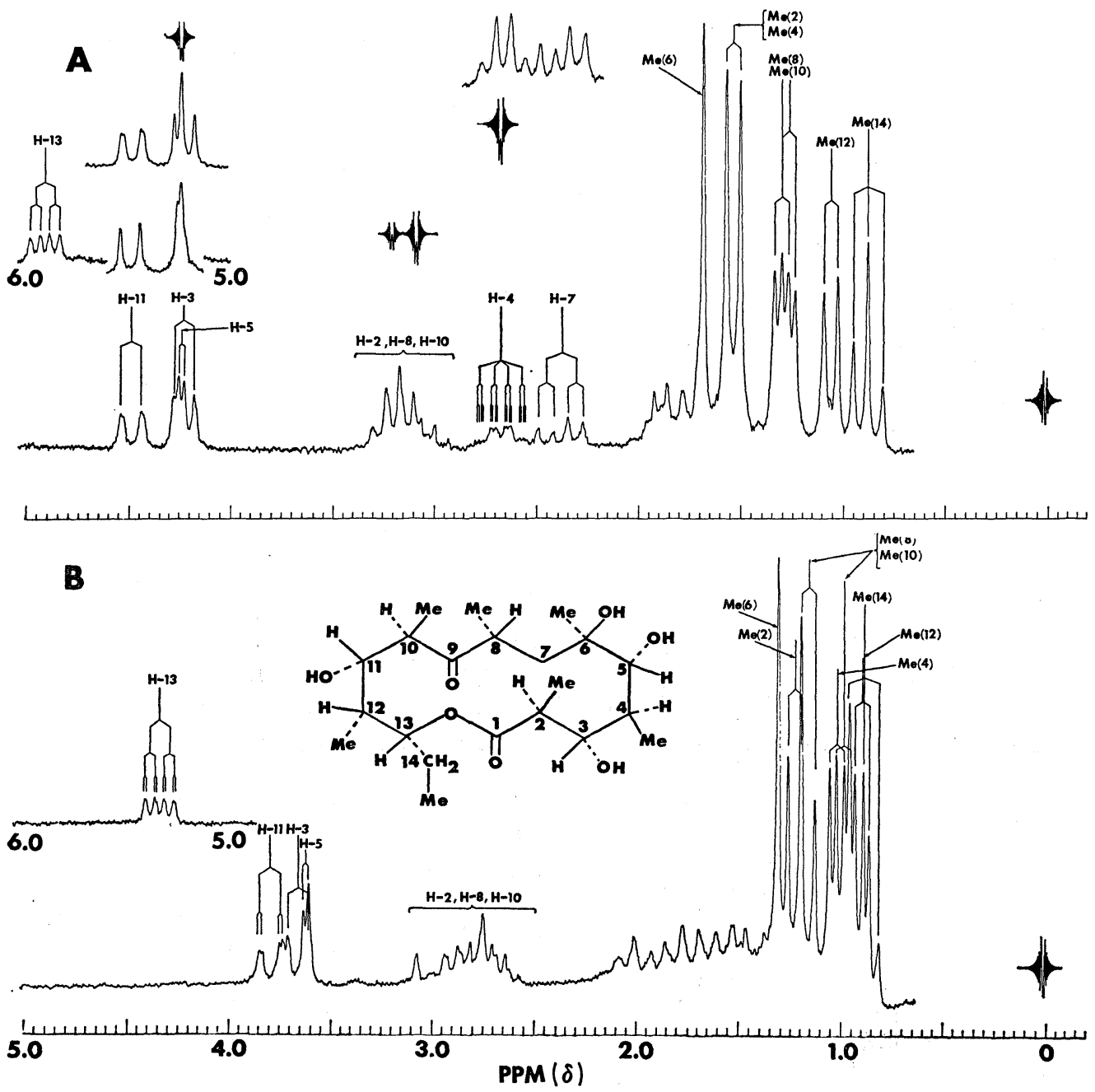

signal which appears as a quartet of doublets (coupled to three protons; $\mathrm{J}=9.4,4.8$ and $1.0 \mathrm{~Hz}$ ) centered at $\delta 5.90, \delta 5.67$, and $\delta 5.80$ in the spectra of III, IV and V respectively (Figs. 1A, 2A and $3 \mathrm{~A}$ ) and as a doublet of doublets (coupled to two protons; $\mathrm{J}=10.3$ and $2.2 \mathrm{~Hz}$ ) centered at $\delta 5.68$ in the spectrum of VI (Fig. 4A). These assignments are based on the fact that, (i) $\mathrm{H}-13$ is located on the carbon bonded directly to the lactone ether oxygen and is consequently expected to resonate to lowest field of all aglycone ring protons because of the combined inductive and long-range screening effects of ether oxygen and carbonyl function respectively and, (ii) replacement of the C-12 proton in III, IV and V with an $\mathrm{OH}$ function, as in IV, results in decreased coupling for this signal (i.e., a quartet of doublets becomes a doublet of doublets; compare Figs. 1A, 2A and $3 \mathrm{~A}$ with $4 \mathrm{~A}$ ) thus verifying its location adjacent to the $\mathrm{C}$ 12 position. The magnitude of coupling between $\mathrm{H}-13$ and adjacent vicinal protons 
in III, IV and $\mathrm{V}$ is observed to be as follows: $\mathrm{J}_{12,13}=1.0 \mathrm{~Hz}^{\mathrm{e}, \mathrm{f})}, \mathrm{J}_{13,14}=4.8 \mathrm{~Hz}$ and $\mathrm{J}_{13,14^{\prime}}=9.4 \mathrm{~Hz}$.

Because of their splitting pattern, the doublet of quartet signals $(\mathrm{J}=6.8$ and 10.1 $\mathrm{Hz}$ ), centered at $\delta 3.05, \delta 3.03$ and $\delta 3.07$ in the spectra of IV, V and VI respectively (Figs. 2A, 3A and 4A), can arise only from protons situated on carbon atoms bearing methyl groups, i.e., from either methine protons $\mathrm{H}-2, \mathrm{H}-4, \mathrm{H}-8, \mathrm{H}-10$ or $\mathrm{H}-12$. H-12

Fig. 2. PMR spectrum of 9-dihydroerythronolide B (compound IV) in pyridine- $d_{5}(A)$ and deuteriochloroform (B).

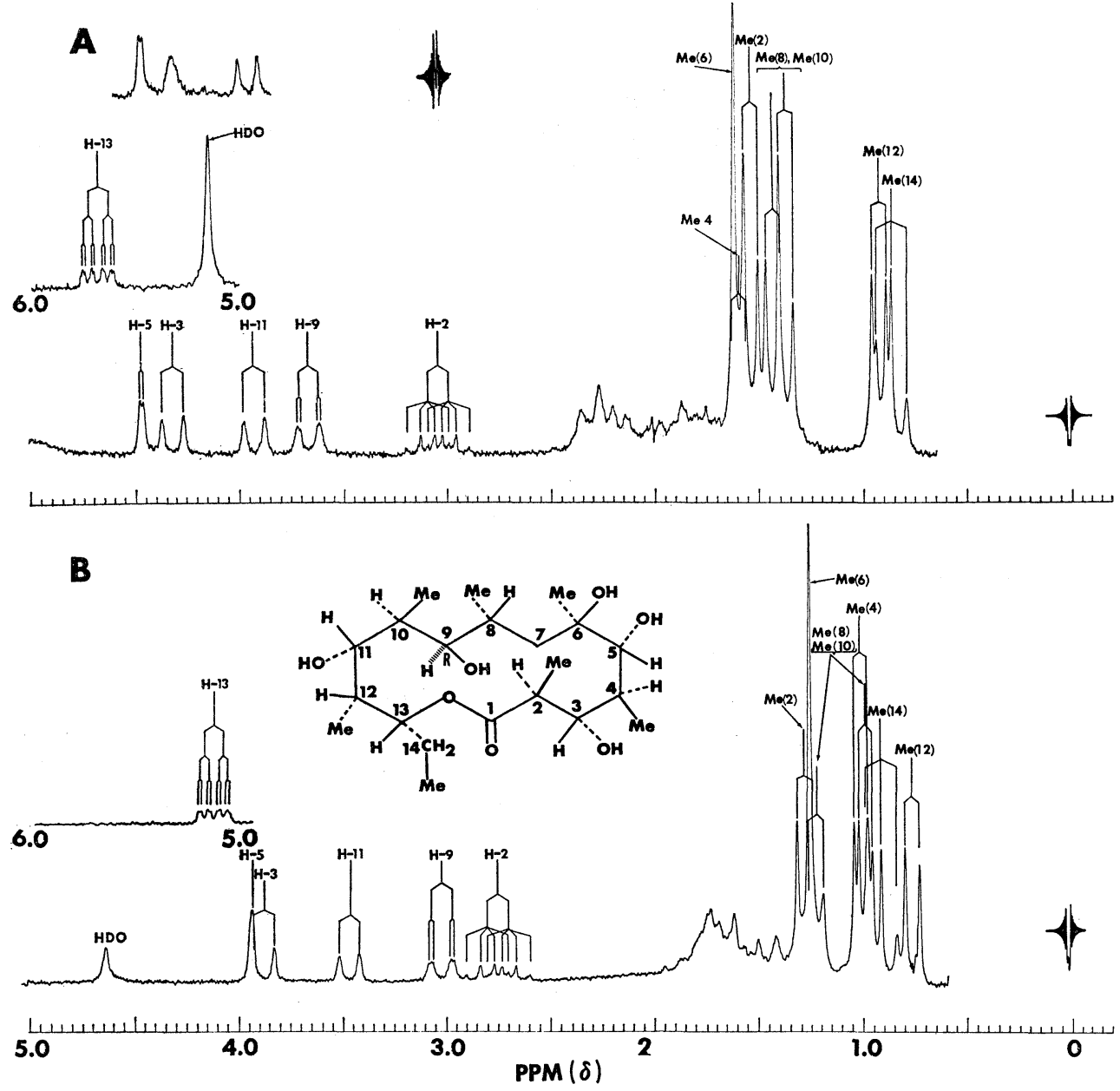

e) Since both $J_{13,14}$ and $J_{13,14^{\prime}}$ in III, IV and $\mathrm{V}$ have slightly different values from those observed in VI, presumably resulting from conformational differences in the ethyl side chain occasioned by differences in steric requirements of substituents at C-12 in these systems, some doubt arises as to the validity of assigning $J_{12,13}=1.0 \mathrm{~Hz}$ in III, IV and V. This value for $J_{12,13}$, however, has been recently verified by observation of a $1.0 \mathrm{~Hz}$ splitting in the $\mathrm{H}-12$ signal in derivatives where this signal is far enough downfield to be independently observed ${ }^{f}$. This confirms the erroneousness of the earlier assigned coupling for $\mathrm{J}_{12,13}(4.8 \mathrm{~Hz})$ and indicates a slight modification to the previously proposed aglycone conformation ${ }^{1)}$. From $\mathrm{J}_{12,13}=1.0 \mathrm{~Hz}$, a $\phi$-value of $70^{\circ}$ or $105^{\circ}$ is calculated which, when considered with other pertinent nmr data, yields the corrected conformation shown in Fig. 5. This conformation differs only at the $\mathrm{C}-12$, C-13 ring positions from that reported earlier ${ }^{1)}$.

f) T. J. Perun : Private communication. 
can be immediately eliminated as a possibility since this doublet of quartets signal is present in the spectrum of compound VI which, unlike IV and V contains no proton the C-12 position. Since first-order spectral analysis indicates that the proton responsible for the doublet of quartets signal is coupled vicinally to only one aglycone ring proton, $\mathrm{H}-2$ is strongly indicated since $\mathrm{H}-4, \mathrm{H}-8$ and $\mathrm{H}-10$ are all situated adjacent to more than one methine proton. This assignment is further supported by the low field chemical shift position of these signals, i.e., at approximately $3 \mathrm{ppm}$, which is indicative of protons situated adjacent to a carbonyl function ${ }^{16)}$.

Irradiation at $\mathrm{H}-2$ in the spectra of IV, V and VI (Figs. 2A, 3A and 4A) causes the collapse, (to singlets) of carbinol methine doublets centered at $\delta 4.25, \delta 4.24$ and $\delta 4.26(\mathrm{~J}=10.1 \mathrm{~Hz})$ respectively and methyl doublets centered at $\delta 1.53, \delta 1.52$ and $\delta 1.52$ $(\mathrm{J}=6.8 \mathrm{~Hz})$ respectively. These sets of signals are accordingly assigned to the $\mathrm{G}-3$ protons and the $\mathrm{C}-2$ methyl protons respectively.

Fig. 3. PMR spectrum of 9-dihydroerythronolide B (compound V) in pyridine $-\mathrm{d}_{5}(A)$ and deuteriochloroform (B).

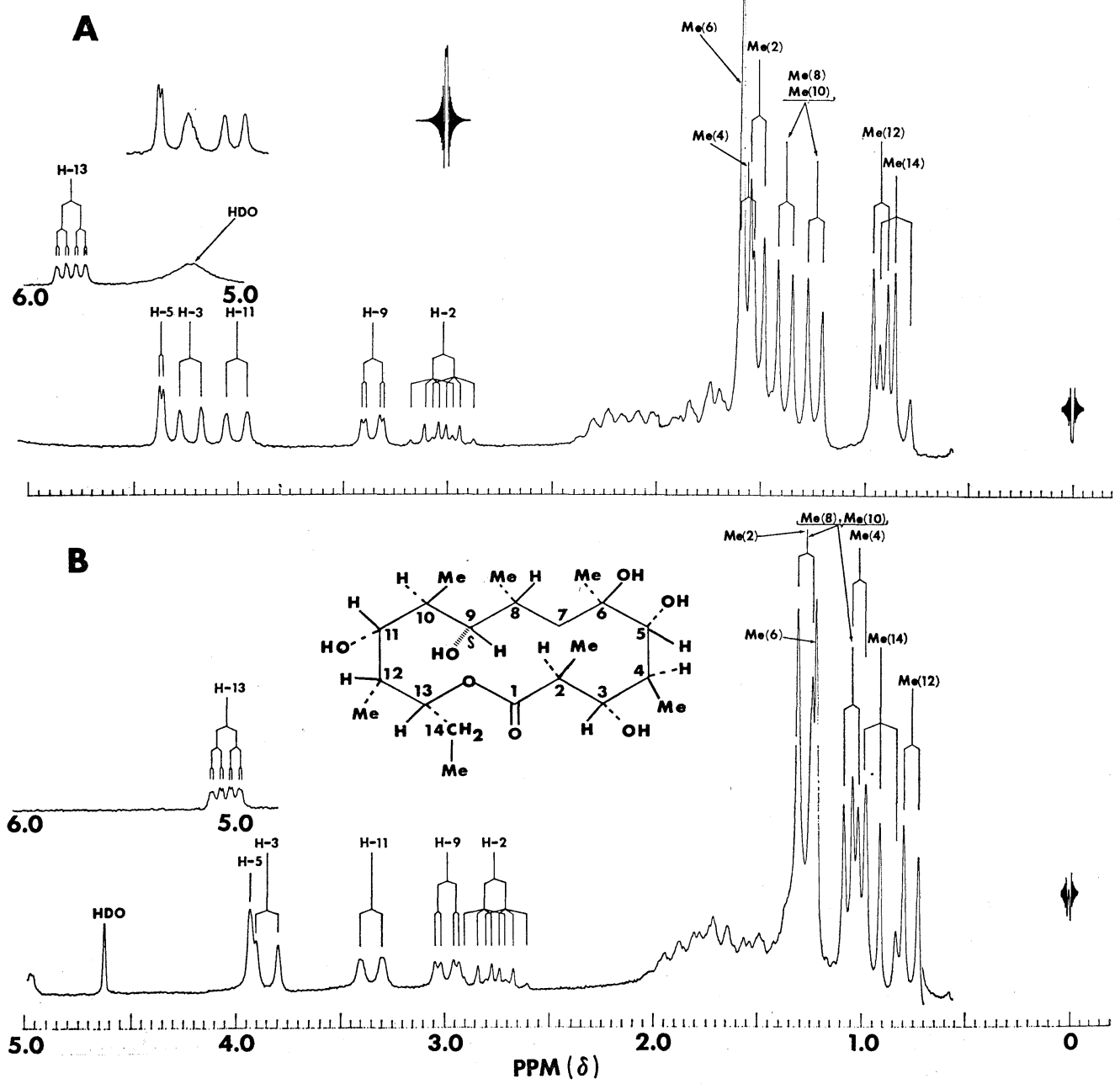


Irradiation at the $\mathrm{H}-3$ signal in $\mathrm{IV}, \mathrm{V}$ and VI causes the doublet of quartets signal of $\mathrm{H}-2$ to reduce to a quartet $\left(\mathrm{J}_{2,2 \mathrm{CH}_{3}}=6.8 \mathrm{~Hz}\right)$ with no other perceptible spectral changes noted. This indicates that, as $\mathrm{H}-4$ is located on a carbon bearing no electronegative substituent, the signal arising from this proton must resonate in the methylenemethine region $(\delta 1.2 \sim 2.2)$ and is consequently not directly observable. A simple spindecoupling experiment confirms the presence of $\mathrm{H}-4$ in this region and conveniently identifies the H-5 signal. Thus, application of a saturating frequency at approximately $\delta 2.3 \sim 2.4$ results in increased signal sharpening for the $\mathrm{H}-3$ doublets $\left(\mathrm{J}_{2,3}=10.1 \mathrm{~Hz}\right)$, indicating slight coupling to $\mathrm{H}-4\left(\mathrm{~J}_{3,4}\right)<1.0 \mathrm{~Hz}$ ), and the collapse (to singlets) of doublets centered at $\delta 4.39, \delta 4.37$ and $\delta 4.39$. These latter signals, which are accordingly assigned to the $\mathrm{C}-5$ protons in compounds $\mathrm{IV}, \mathrm{V}$ and VI respectively, reveal $\mathrm{J}_{4,5}=1.7 \mathrm{~Hz}$.

Fig. 4. PMR spectrum of 9-dihydroerythronolide A (VI) in pyridine $-d_{5}(A)$ and deuteriochloroform (B).
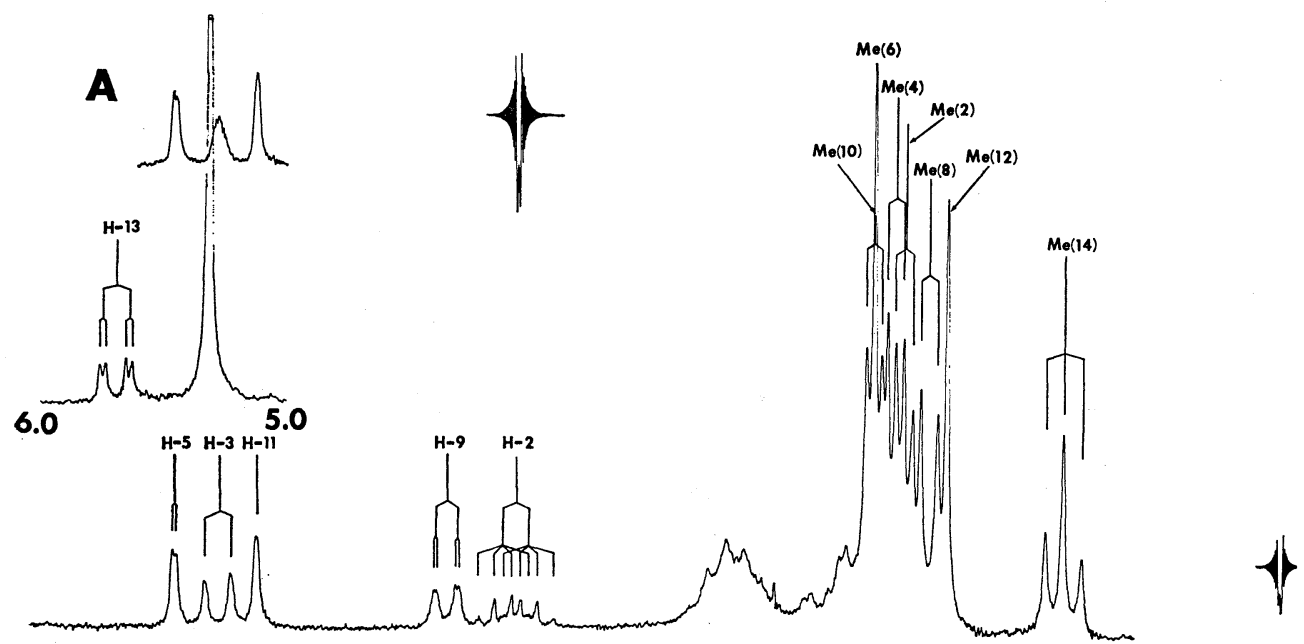

B
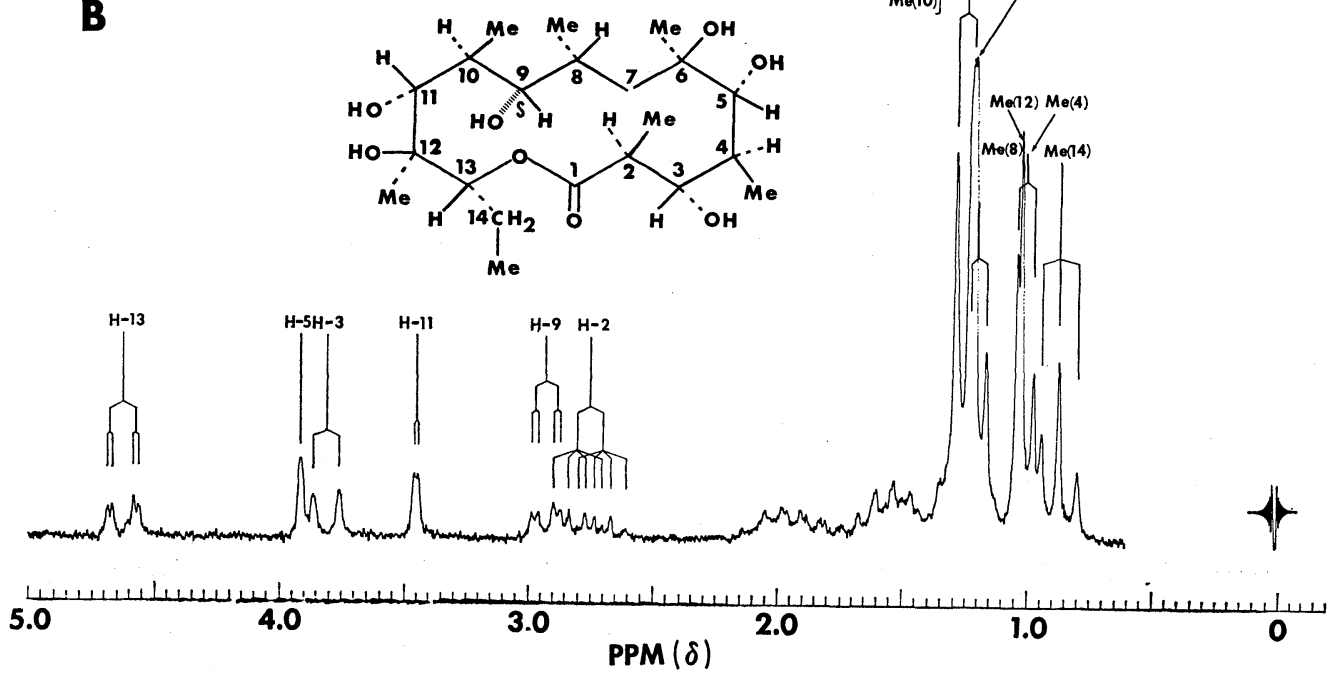
Table 1. Observed chemical shifts* $(\delta)$ and coupling constants** $(\mathrm{Hz})$ for aglycone ring protons and methyl groups in systems studied

\begin{tabular}{|c|c|c|c|c|}
\hline \multirow{2}{*}{ Resonance } & \multirow{2}{*}{$\begin{array}{c}\text { Erythronolide B } \\
\text { III }\end{array}$} & \multicolumn{2}{|c|}{ 9-Dihydroerythronolides B } & \multirow{2}{*}{$\begin{array}{c}\text { Dihydroery thronolide } \\
\text { A } \\
\text { VI }\end{array}$} \\
\hline & & IV & $\mathrm{V}$ & \\
\hline $\mathrm{H}-2$ & $\begin{array}{l}(2.53 \sim 3.08) \mathrm{m} \\
{[2.90 \sim 3.33] \mathrm{m}}\end{array}$ & $\begin{array}{l}(2.75) \mathrm{dq} \mathrm{J}_{2,3}=10.1 \\
{[3.05] \mathrm{dq} \mathrm{J}_{2,3 \mathrm{CH} 3}=6.8}\end{array}$ & $\begin{array}{ll}(2.76) \mathrm{dq} & \mathrm{J}_{2,3}=10.1 \\
{[3.03] \mathrm{dq}} & \mathrm{J}_{2,3 \mathrm{CH}_{3}}=6.8\end{array}$ & $\begin{array}{l}(2.78) \mathrm{dq} \mathrm{J}_{2,3}=10.1 \\
{[3.07] \mathrm{dq} \mathrm{J}_{2,2 \mathrm{CH} 3}=6.8}\end{array}$ \\
\hline $\mathrm{H}-3$ & $\begin{array}{l}(3.65) \mathrm{d} \\
{[4.23] \mathrm{d}}\end{array} \quad \mathrm{J}_{3,2}=10.1$ & $\begin{array}{l}(3.86) \mathrm{d} \\
{[4.25] \mathrm{d}}\end{array} \mathrm{J}_{3,2}=10.1$ & $\begin{array}{l}(3.84) \mathrm{d} \\
{[4.24] \mathrm{d}}\end{array} \mathrm{J}_{3,2}=10.1$ & $\begin{array}{l}(3.85) \mathrm{d} \\
{[4.26] \mathrm{d}}\end{array} \quad \mathrm{J}_{3,2}=10.1$ \\
\hline $\mathrm{H}-4$ & $\begin{array}{l}{[2.67] \mathrm{qq} ; \mathrm{J}_{4,5}=2.5,} \\
\quad \mathrm{~J}_{4,3} \simeq 1, \mathrm{~J}_{4,4 \mathrm{CH}_{3}}=6.8\end{array}$ & & & \\
\hline $\mathrm{H}-5$ & $\begin{array}{l}(3.61) \mathrm{d} \\
{[4.24) \mathrm{d}}\end{array} \mathrm{J}_{5,4}=2.5$ & $\begin{array}{ll}(3.94) \mathrm{bs} & \mathrm{J}_{5,4} \simeq 1.0 \\
{[4.39] \mathrm{d}} & \mathrm{J}_{54}=1.7\end{array}$ & 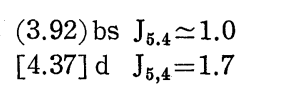 & $\begin{array}{ll}(3.92) \mathrm{bs} & \mathrm{J}_{5.4} \simeq 1.0 \\
{[4.39] \mathrm{d}} & \mathrm{J}_{5,4}=1.7\end{array}$ \\
\hline $\mathrm{H}-7$ & $\begin{array}{l}{[2.37] \mathrm{dd}} \\
\quad \mathrm{J}_{7,7^{\prime}}=14.5, \mathrm{~J}_{7,8}=8.0\end{array}$ & & & \\
\hline $\begin{array}{l}\mathrm{H}-8 \\
\mathrm{H}-10\end{array}$ & $\begin{array}{l}(2.53 \sim 3.08) \mathrm{m} \\
{[2.90 \sim 3.33] \mathrm{m}}\end{array}$ & & & \\
\hline $\mathrm{H}-9$ & & $\begin{array}{l}(3.02) \text { dd } \mathrm{J}_{9,10}=10.1 \\
{[3.68] \text { dd } \mathrm{J}_{9,8} \simeq 1.8}\end{array}$ & $\begin{array}{ll}(2.99) \text { dd } & J_{9,8}=1.8 \\
& J_{9,10}=9.0 \\
{[3.37] \text { dd }} & J_{9,8}=2.5 \\
& J_{9,10}=9.0\end{array}$ & $\begin{array}{ll}(2.96) \text { dd } & J_{9,8}=1.8 \\
& J_{9,10}=9.0 \\
{[3.36] \text { dd }} & J_{9,8}=2.5 \\
& J_{9,10}=9.0\end{array}$ \\
\hline $\mathrm{H}-11$ & $\begin{array}{l}(3.79) \text { dd } \mathrm{J}_{11,12}=10.1 \\
{[4.48] \text { dd } \mathrm{J}_{11,10}=1.5}\end{array}$ & $\begin{array}{l}(3.47) \mathrm{bd} \\
{[3.93] \mathrm{bd}}\end{array} \mathrm{J}_{11,12}=10.1$ & $\begin{array}{l}(3.35) \mathrm{d} \\
{[4.10] \mathrm{d}}\end{array} \quad \mathrm{J}_{11,12}=10.1$ & $\begin{array}{l}(3.48) \mathrm{s} \\
{[4.12] \mathrm{s}}\end{array}$ \\
\hline $\mathrm{H}-13$ & $\begin{array}{ll}(5.34) \mathrm{dq} & \mathrm{J}_{13,14^{\prime}}=9.4 \\
{[5.90] \mathrm{dq} .} & \mathrm{J}_{13,14}=4.8 \\
& \mathrm{~J}_{13,12}=1.0\end{array}$ & $\begin{array}{ll}(5.11) \mathrm{dq} & \mathrm{J}_{13,14^{\prime}}=9.4 \\
{[5.67] \mathrm{dq}} & \mathrm{J}_{13,14}=4.8 \\
& \mathrm{~J}_{13,12}=1.0\end{array}$ & $\begin{array}{ll}(5.04) \mathrm{dq} & \mathrm{J}_{13,14^{\prime}}=9.4 \\
{[5.80] \mathrm{dq}} & \mathrm{J}_{13,14}=4.8 \\
& \mathrm{~J}_{13,12}=1.0\end{array}$ & $\begin{array}{l}(4.63) \mathrm{dd} \quad \mathrm{J}_{13,14}=2.2 \\
{[5.68] \mathrm{dd} \quad \mathrm{J}_{13,1^{\prime}}=10.3}\end{array}$ \\
\hline $2-\mathrm{CH}_{3}$ & $\begin{array}{l}(1.22) \mathrm{d} \\
{[1.53] \mathrm{d}}\end{array} \mathrm{J}_{2,2 \mathrm{CH} 3}=6.8$ & $\begin{array}{l}(1.28) \mathrm{d} \\
{[1.53] \mathrm{d}}\end{array} \mathrm{J}_{22 \mathrm{CH}_{3}}=6.8$ & $\begin{array}{l}(1.27) \mathrm{d} \\
{[1.52] \mathrm{d}}\end{array}$ & $\begin{array}{l}(1.29) \mathrm{d} \\
{[1.52] \mathrm{d}}\end{array}$ \\
\hline $4-\mathrm{CH}_{3}$ & $\begin{array}{l}(1.01) \mathrm{d} \\
{[1.53] \mathrm{d}}\end{array} \mathrm{J}_{4,4 \mathrm{CH}_{3}}=6.8$ & $\begin{array}{l}(1.06) \mathrm{d} \\
{[1.59] \mathrm{d}}\end{array} \mathrm{J}_{4,4 \mathrm{CH}_{3}}=6.8$ & $\begin{array}{l}(1.01) \mathrm{d} \\
{[1.57] \mathrm{d}}\end{array} \mathrm{J}_{4,4 \mathrm{CH} 3}=6.8$ & $\begin{array}{l}(1.02) \mathrm{d} \\
{[1.57] \mathrm{d}}\end{array} \mathrm{J}_{4,4 \mathrm{CH}_{3}}=6.8$ \\
\hline $6-\mathrm{CH}_{3}$ & $\begin{array}{l}(1.30) \mathrm{s} \\
{[1.68] \mathrm{s}}\end{array}$ & $\begin{array}{l}(1.25) \mathrm{s} \\
{[1.62] \mathrm{s}}\end{array}$ & $\begin{array}{l}(1.22) \mathrm{s} \\
{[1.60] \mathrm{s}}\end{array}$ & $\begin{array}{l}(1.34) \mathrm{s} \\
{[1.63] \mathrm{s}}\end{array}$ \\
\hline $\begin{array}{l}8-\mathrm{CH}_{3} \\
10-\mathrm{CH}_{3}\end{array}$ & $\begin{array}{l}(1.15) \mathrm{d} \\
(0.98) \mathrm{d} \mathrm{J}_{8,8 \mathrm{CH} 3}=6.8 \\
{[1.26] \mathrm{d} \mathrm{J}_{10,10 \mathrm{CH}_{3}}=6.8} \\
{[1.29] \mathrm{d}}\end{array}$ & $\begin{array}{l}(0.98) \mathrm{d} \\
(1.22) \mathrm{d} \mathrm{J}_{8,8 \mathrm{CH} 3}=6.8 \\
{[1.43] \mathrm{d} \mathrm{J} \mathrm{J}_{10,10 \mathrm{CH} 3}=6.8} \\
{[1.37] \mathrm{d}}\end{array}$ & $\begin{array}{l}(1.05) \mathrm{d} \\
(1.27) \mathrm{d} \mathrm{J}_{8,8 \mathrm{CH}_{3}}=6.8 \\
{[1.24] \mathrm{d} \mathrm{J}_{10,10 \mathrm{CH}_{3}}=6.8} \\
{[1.39] \mathrm{d}}\end{array}$ & $\begin{array}{l}(1.24) \mathrm{d} \\
(1.29) \mathrm{d} \mathrm{J}_{8,8 \mathrm{CH}_{3}}=6.8 \\
{[1.41] \mathrm{d} \mathrm{J}_{10,10 \mathrm{CH}_{3}}=6.8} \\
{[1.64] \mathrm{d}}\end{array}$ \\
\hline $12-\mathrm{CH}_{3}$ & $\begin{array}{l}(0.89) \mathrm{d} \\
{[1.05] \mathrm{d}}\end{array} \mathrm{J}_{12,12 \mathrm{CH}_{3}}=6.8$ & $\begin{array}{l}(0.76) \mathrm{d} \\
{[0.92] \mathrm{d}}\end{array} \mathrm{J}_{12,12 \mathrm{CH}_{3}}=6.8$ & $\begin{array}{l}(0.76) \mathrm{d} \\
{[0.93] \mathrm{d}}\end{array} \mathrm{J}_{12,12 \mathrm{CH}_{3}}=6.8$ & $\begin{array}{l}(1.05) \mathrm{s} \\
{[1.34] \mathrm{s}}\end{array}$ \\
\hline $13-\mathrm{CH}_{3}$ & $\begin{array}{l}(0.88) \mathrm{t} \\
{[0.87] \mathrm{t}}\end{array} \quad \mathrm{J}=7.0$ & $\begin{array}{l}(0.91) \mathrm{t} \\
{[0.86] \mathrm{t}}\end{array} \quad \mathrm{J}=7.0$ & $\begin{array}{l}(0.91) \mathrm{t} \\
{[0.86] \mathrm{t}}\end{array} \quad \mathrm{J}=7.0$ & $\begin{array}{l}(0.90) \mathrm{t} \\
{[0.87] \mathrm{t}}\end{array} \quad \mathrm{J}=7.0$ \\
\hline
\end{tabular}

* Chemical shift values recorded in round and square brackets correspond to shifts measured in deuteriochloroform and pyridine- $\mathrm{d}_{5}$ solvents respectively. All shifts were obtained at $100 \mathrm{MHz}$ and were measured relative to TMS as internal reference. Sample concentrations were maintained at $5 \% \pm 1 \% \mathrm{w} / \mathrm{v}$ in all cases. Small variations in concentration (i.e. ca. $1 \%$ ) had no appreciable effect on resonance positions in either solvent employed.

** Abbreviations used are as follows : s, singlet; d, doublet; $t$, triplet; $q$, quartet; m, multiplet; dq, doublet of quartets; dd, doublet of doublets; bs, broad singlet. 
Assignments of $\mathrm{H}-11$ in the spectra of IV, $\mathrm{V}$ and VI is readily made on the basis of comparative analysis of the spectra of these compounds. Replacement of the C-12 proton in IV and $\mathrm{V}$ with an $\mathrm{OH}$ function, as in VI, causes the broadened doublets $(\mathrm{J}=10.1 \mathrm{~Hz}$ and $<1.0 \mathrm{~Hz})$, centered at $\delta 3.93$ and $\delta 4.01$ in the spectra of IV and $\mathrm{V}$, to reduce to a broadened singlet $(\mathrm{J}<1.0 \mathrm{~Hz}$ ) at $\delta 4.12$ (compare Figs. 2A and $3 \mathrm{~A}$ with Fig. 4A). Coupling constants, $J_{10,11}<1.0 \mathrm{~Hz}$ in $\mathrm{IV}, \mathrm{V}$ and $\mathrm{VI}$ and $\mathrm{J}_{11,12}=10.1 \mathrm{~Hz}$ in IV and $\mathrm{V}$, are calculated from analysis of these $\mathrm{H}-11$ signals.

By process of elimination, H-9 remains as the only unassigned carbinol methine proton. Thus, the remaining doublet of doublet signals centered at $\delta 3.68, \delta 3.37$ and $\delta 3.36$ in the spectra of $\mathrm{IV}, \mathrm{V}$ and VI respectively are assigned to this proton.

Assignment of $\mathrm{H}-3, \mathrm{H}-5$ and $\mathrm{H}-11$ in the spectrum of erythronolide B (III) presented a slightly more difficult task than in the previously discussed 9-dihydroderivatives (IV, V and VI). Irradiation at the center of the three proton multiplet centered at approximately $\delta 3.1$, arising from protons situated on carbon atoms adjacent to the C-1 and C-9 carbonyl functions, causes changes in the coupling patterns of two carbinol methine signals. Thus, broadened doublet signals centered at $\delta 4.23(\mathrm{~J}=10.1$ $\mathrm{Hz}$ and $<1.0 \mathrm{~Hz})$ and at $\delta 4.48(\mathrm{~J}=10.1 \mathrm{~Hz}$ and $1.5 \mathrm{~Hz})$ reduce to a broadened singlet $(\mathrm{J}<1.0 \mathrm{~Hz})$ and sharp doublet $(\mathrm{J}=10.1 \mathrm{~Hz})$ respectively. Comparison of $\mathrm{J}_{10,11}$ and $\mathrm{J}_{2,3}$ values subsequently recorded in III with corresponding values previously recorded in $\mathrm{IV}, \mathrm{V}$ and VI allows these doublets, i.e. at $\delta 4.23$ and $\delta 4.48$, to be assigned to a $\mathrm{H}-3$ and $\mathrm{H}-11$ respectively. Further confirmation of these assignments comes from the analysis of two additional signals, the quartet $(\mathrm{J}=6.8 \mathrm{~Hz})$ of double $(\mathrm{J}=2.5 \mathrm{~Hz})$ doublets $(\mathrm{J}=1.0 \mathrm{~Hz})$ centered at $\delta 2.67$ and the doublet $(\mathrm{J}=15.0 \mathrm{~Hz})$ of $\operatorname{doublets}(\mathrm{J}=7.2 \mathrm{~Hz})$ centered at $\delta 2.37$, which appear at low enough field in pyridine- $\mathrm{d}_{5}$ to be clearly distinguishable (compare Fig. 1A with Fig. 1B). The former signal ( $\delta 2.67)$, because of its coupling pattern, must arise from either the C-4, C-8 or C-12 protons, while the latter signal ( $\delta 2.37)$ is tentatively assigned to one of the $\mathrm{C}-7$ methylene protons because of the large $15 \mathrm{~Hz}$ coupling (indicative of geminal coupling) noted in this signal. Irradiation at $\delta 2.67$ confirms the assignment of this signal to $\mathrm{H}-4$ since two carbinol methine doublets $(\mathrm{H}-3$ and $\mathrm{H}-5)$ centered at $\delta 4.23(\mathrm{~J}=10.1 \mathrm{~Hz}$ and $<1.0 \mathrm{~Hz})$ and $\delta 4.24$ $(\mathrm{J}=2.5 \mathrm{~Hz})$ reduce to a sharp doublet and singlet respectively (Fig. 1A). If this signal were due to $\mathrm{H}-12$, irradiation would have resulted in collapse of the $\mathrm{H}-13$ multiplet and one carbinol methine proton $(\mathrm{H}-11)$, while, if $\mathrm{H}-8$ were responsible, none of the carbinol methine protons would have changed their coupling patterns.

Irradiation at the center of the double doublet signal $(\delta 2.39)$, attributed to one of the C-7 protons, produces no visible changes in other portions of the spectrum of III further supporting this assignment to $\mathrm{H}-7$.

The aglycone ring systems studied contain three types of methyl protons. These can be readily identified on the basis of their signal patterns. Since the $\mathrm{C}-6$ ring position is quaternary, the C-2, C-4, C-8 and C-10 positions tertiary and the C-14 position secondary, methyl protons situated at these positions will appear as singlets, doublets and triplets respectively. The G-12 methyl group which is tertiary in III, IV and $\mathrm{V}$ and quaternary in VI will thus give rise to doublets in the spectra of the 
former and a singlet in the spectrum of the latter respectively. Thus, methyl singlets which appear at $\delta 1.68, \delta 1.62, \delta 1.60$ and $\delta 1.63$ in the spectra of III, IV, V and VI respectively are assigned to the $\mathrm{G}-6$ methyl protons, while triplets arising from the C-14 methyl protons appear at $\delta 0.87, \delta 0.86, \delta 0.86$ and $\delta 0.87$, respectively.

Assignments for the C-2 methyl signals in IV, V and VI $(\delta 1.53, \delta 1.52$ and $\delta 1.52$ respectively) were previously determined by irradiation at the $\mathrm{H}-2$ signal in each system and observing the collapse of the C-2 methyl doublet. In the case of erythronolide B (III), however, chemical shift assignment was, as before, slightly more difficult because of the superimposition of the H-2, H-8 and H-10 signals. Saturation of this three proton multiplet by simultaneous irradiation at $\delta 3.08$ and $\delta 3.20$ (triple resonance) resulted in the collapse of three methyl doublets centered at $\delta 1.53, \delta 1.26$ and $\delta 1.29$ and were assigned to the C-2, C- 8 and C-10 methyl protons. By comparison of these signal positions with the previously assigned $\mathrm{C}-2$ methyl signal positions in IV, $\mathrm{V}$ and VI $(\delta 1.53, \delta 1.52$ and $\delta 1.52$ respectively), the $\delta 1.53$ signal in the spectra of III is assigned to the C-2 methyl protons. This is reasonable since differences in screening at the C-2 methyl group, resulting from functionality differences at C-9 in these systems, should be small because of the large spatial separation between these two positions. The remaining two methyl signals are therefore assigned to the C-8 and C-10 methyl protons.

The C-12 methyl protons can be assigned from comparative analysis. The pyridine spectra of III, IV and V reveal the presence, in each case, of a high field methyl doublet centered at $\delta 1.05, \delta 0.92$ and $\delta 0.93$, respectively in the approximate vicinity of the C-14 methyl triplet (compare spectra $1 \mathrm{~A}, 2 \mathrm{~A}, 3 \mathrm{~A}$ and $4 \mathrm{~A}$ ). In the spectra of VI, however, this high field doublet is absent (as noted by the isolation of the C-14 methyl triplet) and is replaced by a methyl singlet at much lower field ( $\delta 1.34)$. Since the $\mathrm{C}-12$ position in VI is quaternary, the C-12 methyl signal, which normally appears as a doublet in the spectra of III, IV and $\mathrm{V}$ appears as a singlet in the spectrum VI. Moreover, because of anisotropic and solvent deshielding effects (in pyridine) associated with the C-12 hydroxyl function, the G-12 methyl protons resonate at lower field in VI than in III, IV and V.

As all methyl signals, except the C-4 methyl signal, have been assigned in the spectra of erythronolide B (III), this signal, by elimination, is assigned to the methyl doublet centered at $\delta 1.53$. This assignment is further supported by the observation that irradiation at the center of the multiplet signal $(\delta 2.67)$ in III previously assigned to $\mathrm{H}-4$, causes this methyl doublet to reduce to a singlet.

The remaining unassigned doublets in the spectra of IV, V and VI are those arising from the C-4, C-8 and C-10 methyl protons. Once again, by comparison with assignments made for these protons in the spectrum of III, the C-4 methyl protons in IV, $\mathrm{V}$ and VI can be assigned with reasonable certainty. Assuming that differences in functionality at C-9 in these systems produce only marginal screening differences at the C-4 position because of the magnitude of separation, doublets centered at $\delta 1.59$, $\delta 1.57$ and $\delta 1.57$ in the spectra of IV, V and VI are assigned to the C-4 methyl protons in these systems, in good agreement with the C-4 methyl assignment in compound 
III ( $\delta$ 1.53). The remaining two unassigned doublets at $\delta 1.43$ and 1.37 in IV, at $\delta 1.24$ and 1.39 in $\mathrm{V}$ and at $\delta 1.41$ and 1.64 in VI are consequently assigned to the C-8 and C-10 protons.

\section{Conformational and Configurational Analysis}

Information regarding conformational and configurational uncertainties in compounds III, IV, V and VI can now be derived from the nmr data tabulated in Table 1. Structural conclusions concerning these systems evolve from two sources; (i) from observed spin-spin coupling constants ( $\mathrm{J}$-values) for vicinal aglycone ring protons and (ii) from pyridine solvent shift $\Delta$-values for these same protons. Information derived from these sources are discussed in order.

From observed J-values recorded in Table 1, the approximate dihedral angles $(\phi)$ subtended between vicinal ring protons have been calculated utilizing the KARPLus equation $^{17)}$, and are summarized in Table 2. Since the Karplus equation calculates two possible $\phi$ values for each observed Jvicinal value, numerous aglycone conformational possibilities exist. Fortunately, however, information derived from chemical

Table 2. Observed coupling constants $(\mathrm{Hz})$ and dihedral angle estimates for vicinal aglycone ring protons in III, IV, V and VI

\begin{tabular}{c|c|r}
\hline Coupling & $\begin{array}{c}\text { Observed vicinal coupling } \\
\text { for ring protons }\end{array}$ & $\phi$ Calc. (degrees)* \\
\hline $\mathrm{J}_{2,3}$ & 10.1 & 0 or $\frac{140}{10}$ \\
$\mathrm{~J}_{3,4}$ & $<1.0$ & 70 or 105 \\
$\mathrm{~J}_{4,5}$ & $2.5 \sim 1.0$ & $60 \sim 70$ or $105 \sim 115$ \\
$\mathrm{~J}_{8,9}$ & 1.8 & 65 or 110 \\
$\mathrm{~J}_{9,10}$ & $9.0 \sim 10.0$ & $0 \sim 15$ or $135 \sim 140$ \\
$\mathrm{~J}_{10,11}$ & $<1.0$ & 70 or $\frac{105}{10}$ \\
$\mathrm{~J}_{11,12}$ & 10.1 & 0 or $\frac{140}{105}$ \\
$\mathrm{~J}_{12,13}$ & $<1.0$ & 70 or 105 \\
\hline
\end{tabular}

* The CARPLUs equation results in the calculation of two possible dihedral angle values. The angles underlined are those which are most compatible with solvent shift findings and were thus utilized in deriving aglycone ring conformation.

Table 3. Pyridine $\Delta$-values $\left(\Delta=\delta \mathrm{CDCl}_{3}-\delta \mathrm{C}_{5} \mathrm{D}_{5} \mathrm{~N}\right)$ in ppm for various aglycone ring protons in 9-dihydroerythronolides

\begin{tabular}{c|c|c|c}
\hline \multirow{2}{*}{ Resonance } & \multicolumn{2}{|c|}{ 9-Dihydroerythronolides B } & 9-Dihydroerythronolide A \\
\cline { 2 - 3 } & IV & $\mathrm{V}$ & VI \\
\hline H-2 & -0.30 & -0.27 & -0.29 \\
$\mathrm{H}-3$ & -0.38 & -0.40 & -0.41 \\
$\mathrm{H}-5$ & -0.45 & -0.44 & -0.47 \\
$\mathrm{H}-9$ & -0.66 & -0.38 & -0.40 \\
$\mathrm{H}-11$ & -0.46 & -0.66 & -0.64 \\
$\mathrm{H}-13$ & -0.56 & -0.76 & $-0.80^{*}$ \\
$2-\mathrm{Me}$ & -0.25 & -0.25 & -0.23 \\
$4-\mathrm{Me}$ & -0.58 & -0.56 & -0.55 \\
$6-\mathrm{Me}$ & -0.37 & -0.38 & -0.39 \\
$12-\mathrm{Me}$ & -0.16 & -0.17 & -0.29 \\
$14-\mathrm{Me}$ & +0.05 & +0.05 & +0.03 \\
\hline
\end{tabular}

* See foot-note $\mathrm{h}$ ). 
shift data yields further spatial restrictions making conformational assignment considerably less ambiguous.

Previous studies have demonstrated the existence of a number of pyridine solvent shift-structure relationships in compounds containing the hydroxyl function ${ }^{8 \sim 13)}$. Several of the relationships derived are relevant to the present study ${ }^{\mathrm{g}}$. From assigned shift values recorded for various ring protons and methyl groups in both deuteriochloroform and pyridine- $\mathrm{d}_{5}$ solvents (Table 1 ), pyridine 4 -values are calculated and are recorded in Table 3. Analysis of these values leads to the following conclusions.

Compounds III, IV, V and VI are conformationally homogenous in solution, i.e., they adopt the same approximate conformation.-Since it has been previously established that the magnitude of shifts induced in pyridine is dependent upon the relative spatial position of the proton and hydroxyl function under consideration ${ }^{8 \sim 13)}$, the constant $\Delta$-values noted for protons and methyl groups situated at ring positions 2 , 3, 4, 5 and 6 (Table 3) conclusively demonstrate that their spatial position relative to nearby polar substituents is the same in IV, V and VI. In addition, these protons. must be situated distant enough from the G-9 or G-12 positions to be independent of screening changes resulting from functional or configurational differences at these positions. Proton-proton coupling data provide further support for these conclusions since it is observed that the coupling constants for protons at corresponding ring positions (i.e., at 2, 3, 4, 5, 8, 9, 10, 11, 12 and 13) in compounds III, IV, V, and VI are the same (Table 2).

The configuration of the C-9 hydroxyl function is the same in V and VI but different from that in IV. Identical $\Delta$-values (within the limits of experimental error, $\pm 0.03 \mathrm{ppm}$ ) for $\mathrm{H}-9, \mathrm{H}-11$ and $\mathrm{H}-13$ in compounds $\mathrm{V}$ and VI, which differ from 4 -values for corresponding protons in compound IV, confirm this point (Table 3 ) and indicate that these protons are located spatially similar positions relative to the C-9 $\mathrm{OH}$ function in $\mathrm{V}$ and VI.

The C-9 hydroxyl function is spatially proximal to $\mathrm{H}-11$ and $\mathrm{H}-13$ in $\mathrm{V}$ and VI but spatially remote from these protons in IV. From Table 3, it is observed that the C-11 and C-13 protons ${ }^{\mathrm{h})}$ are more strongly deshielded in V and VI than in IV. Since, as was pointed out earlier, compounds IV, V and VI are conformationally homogeneous systems, the greater deshielding observed for $\mathrm{H}-11$ and $\mathrm{H}-13$ in $\mathrm{V}$ and VI, as compared to IV, must be attributed to differences in their spatial relationship with respect to the G-9 hydroxyl function. As C-9 OH is located neither vicinal nor

g) Solvent shift-structure relationships derived previously ${ }^{8}$ and referred to in this work are as follows : (i) 1,3-diaxial proton-hydroxyl function solvent deshielding and (ii) vicinal protonhydroxyl function solvent deshielding.

h) The $\Delta$-value recorded in Table 3 for $\mathrm{H}-13$ in compound VI has been previously corrected for that portion of the total solvent shift $\left(\Delta_{\mathrm{obs}}=-1.50 \mathrm{ppm}\right)$ originating from the adjacent $\mathrm{C}-12 \mathrm{OH}$ function since this function does not occur in compounds III $\sim$ V. This is conveniently accomplished in the following manner : From the known approximate dihedral angle subtended between the $\mathrm{C}_{13}-\mathrm{H}$ and $\mathrm{C}_{12}-\mathrm{OH}$ bonds $\left(\phi=70^{\circ}\right)$, as calculated by the KARpLUs relationship, a $\Delta$-value of approximately $-0.25 \mathrm{ppm}$ is determined from the empirically derived vicinal proton-hydroxyl function solvent deshielding relationship ${ }^{8}$. Thus,

$$
\Delta_{\text {net }}=\Delta_{\text {obs }}-(-0.25)=-1.05+0.25=-0.80 \mathrm{ppm}
$$


geminal to $\mathrm{H}-11$ or $\mathrm{H}-13$, the greater deshielding observed for these protons in $\mathrm{V}$ and VI can only be rationalized if they are situated 1,3-diaxial and pseudo-1,3-diaxial ${ }^{\text {i) }}$ (i.e., 1,5-diaxial) to the $\mathrm{C}-9$ hydroxyl function ${ }^{12)}$. Where the $\mathrm{C}-9$ hydroxyl function has the opposite configuration, as in IV, these interactions are absent, with the result that $\mathrm{H}-11$ and $\mathrm{H}-13$ experience only marginal deshielding effects from the $\mathrm{C}-9 \mathrm{OH}$.

The C-10 methyl protons in VI are situated 1,3-diaxial to the $\mathrm{C}-12 \mathrm{OH}$ function.

This conclusion follows from the observed lower field resonance position for the $\mathrm{C}-10$ methyl group in VI $(\delta 1.64)$ relative to $\mathrm{V}(\delta 1.24)$. Since the only difference in structure between $\mathrm{V}$ and $\mathrm{VI}$ is in the functionality at $\mathrm{G}-12$, this observation can be rationalized only if the $\mathrm{C}-10$ methyl group in VI is situated, spatially, 1,3-diaxial to $\mathrm{C}-12 \mathrm{OH}$. It is further concluded that, as compounds III $\sim$ VI have been demonstrated to be conformationally homogeneous, similar spatial relationships exist between $\mathrm{H}-12$ and the C-10 methyl group in compounds III, IV and V.

The C-12 methyl protons are located distant from all ring hydroxyl functions and/or in the diamagnetic shielding region of the lactone carbonyl function. From an analysis of the spectra of compounds III $\sim \mathrm{V}$ (Figs. $1 \mathrm{~A}, 2 \mathrm{~A}$ and $3 \mathrm{~A}$ ), it is seen that the C-12 methyl protons consistently resonate at considerably higher field than all other aglycone methyl protons with the exception, in some cases, of the C-14 methyl protons. The high field position for the $\mathrm{C}-12$ methyl protons is interpreted to indicate that these protons are situated either in spatial positions, relative to ring hydroxyl functions, not conducive to solvent deshielding ${ }^{8)}$ and/or in the diamagnetic shielding region of the lactone carbonyl function ${ }^{18)} i . e$., situated near the axis normal to the plane of the carbonyl function.

Joint consideration of the above findings frum solvent shift studies, together with dihedral angle estimates calculated for vicinal ring protons indicates that the aglycone conformation portrayed in Fig. 5 is the one most compatible with all the observed facts. The two conformational projections shown clearly indicate the spatial relationships inferred from solvent shift studies and coupling data and demonstrates that in $\mathrm{V}$ and $\mathrm{VI}$, where $\Delta$-values necessitate spatial proximity between the $\mathrm{C}-9 \mathrm{OH}$ function

Fig. 5. Solution conformation of erythromycin aglycone as proposed by nmr (top and side view).

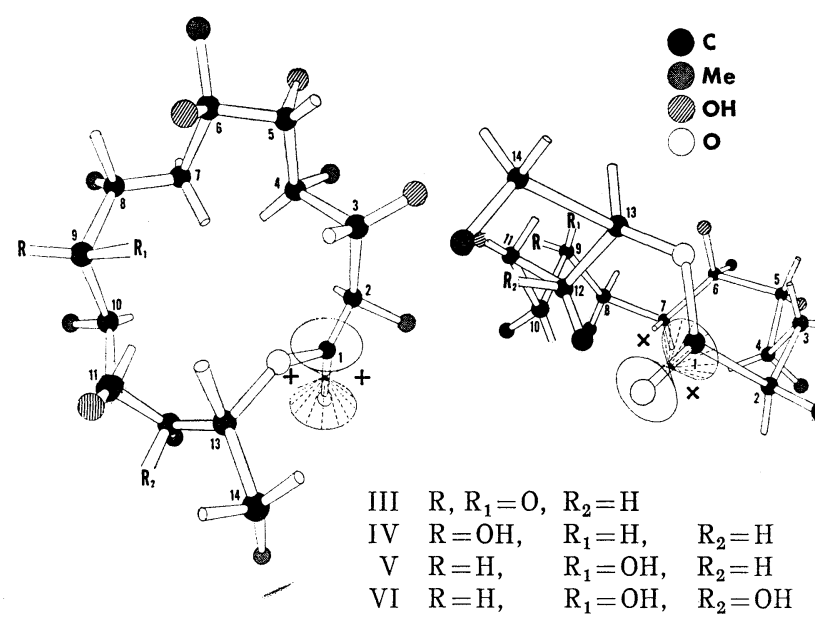

i) The term, "pseudo 1,3-diaxial" implies that though a proton and OH group may be separated by more than three carbon atoms, aglycone conformation may be such as to allow 1,3-diaxial like spatial relationships to exist between them. 
and $\mathrm{H}-11$ and $\mathrm{H}-13$, the configuration at $\mathrm{C}-9$ must be $S$. In IV, where this is not a necessary requirement, the $R$ configuration is assigned to the asymmetry at the C-9 position $^{\mathrm{j})}$. The solution conformation of these macrolides, as defined by pmr, bears considerable resemblance to the conformation proposed by CELMER ${ }^{15)}$ for the related antibiotic oleandomycin and is also in remarkably good agreement with conformation derived by $\mathrm{X}$-ray analysis for erythromycin A aglycone ${ }^{14)}$.

One point of conformational difference, however, does exist between this and previously derived aglycone conformations ${ }^{2,14,15)}$; this is in the precise orientation of the C-11 hydroxyl function. These previous studies define aglycone conformation such that the C-11 hydroxyl group is 'axially' oriented (1,3-diaxial to the C-9 keto function) with $\mathrm{H}-11$ directed 'equatorially' toward the center of the ring, while, from our $\mathrm{nmr}$ observations, it would appear that in solution the C-11 hydroxyl group is directed ' equatorially' away from the center of the ring with $\mathrm{H}-11$ ' axially' oriented (Fig. 5). Chemical evidence would appear to more strongly support the X-ray conformation since it has been recently shown that the cyclic phenylboronate of 9S-dihydroerythronolide $\mathrm{B}(\mathrm{V})$ involves the $\mathrm{C}-9$ and $\mathrm{C}-11 \mathrm{OH}$ functions ${ }^{\mathrm{f}}$, thus necessitating spatial proximity betwen these two functions in the parent dihydroerythronolide ${ }^{\mathrm{k})}(\mathrm{V})$. It is difficult, however, to reconcile pmr observations with this C-11 hydroxyl orientation since this conformation would require $\mathrm{H}-11$ and $\mathrm{H}-13$ to be unadvantageously situated, relative to $\mathrm{C}-9 \mathrm{OH}$, for solvent deshielding (i.e., $\mathrm{H}-13$ would be too remote from $\mathrm{C}-9$ and $\mathrm{H}-11$ would not be situated 1,3-diaxial to $\mathrm{C}-9 \mathrm{OH}$ in $\mathrm{V}$ and VI). This is clearly not observed to be the case (Table 3 ). The apparent anomaly between this and the other ${ }^{2,14,15)}$ proposed aglycone conformation is currently being investigated.

\section{Acknowledgements}

The author would like to express his appreciation to Dr. K. Gerzon for helpful discussions during the course of this work and to Mr. W. E. KRUse for the three-dimensional drawings of aglycone conformation illustrated in Fig. 5.

\section{References}

1) Demarco, P. V. : Pyridine solvent shifts in the nmr analysis of erythromycin aglycones. Tetrahedron Letters 1969-5:383 386, 1969

2) Perun, T. J. \& R. S. EGAN : The conformation of erythromycin aglycones. Tetrahedron Letters 1969-5 : 387 390, 1969

3) Hung, P. P.; C. L. Marks \& P. L. TARDrew : The biosynthesis and metabolism of erythromycins by Streptomyces erythreus. J. Biol. Chem. $240: 1322 \sim 1326,1965$

4) Martin, J. R. \& T. J. Perun : Studies on the biosynthesis of erythromycins. III. Isolation and structure of 5-deoxy-5-oxoerythronolide B, a shunt metabolite of erythromycin biosynthesis. Biochemistry $7: 1728 \sim 1733,1968$

5) Wiley, P. F.; M. V. Sigal, O. Weaver, R. Monahan \& K. Gerzon : Erythromycin. XI. Structure of erythromycin B. J. Am. Chem. Soc. $79: 6070 \sim 6074,1957$

6) Gerzon, K.; E. H. Flynn, M. V. Sigal, P. F. Wrley, R. Monahan \& U. C. Quark : Erythromycin. VIII. Structure of dihydroerythronolide. J. Am. Chem. Soc. $78: 6396 \sim 6408,1956$

7) Slomp, G. \& F. MacKellar : Nuclear magnetic resonance studies using pyridine solutions. J. Am. Chem. Soc. 82 : 999 1000, 1960

j) These configurational assignments of $R$ and $S$ for IV and V, respectively, are in agreement with assignments made for these compounds in another study from chemical evidence (J. R. MARTIN and T. J. Perun, in press). We thank these authors for communicating these results to us.

k) This evidence cannot, at present, be considered conclusive since cyclic ester formation could have been preceeded by aglycone ring conformational changes during chemical reaction. 
8) Demarco, P. V.; E. Farkas, D. Doddrell, B. L. Banavara \& E. Wenkert : Pyridine-induced solvent shifts in the nuclear magnetic resonance spectra of hydroxylic compounds. J. Am. Chem. Soc. 90 : 5480 5486, 1968

9) Huitric, A. C.; J. B. CARr \& W. F. Trager : NMR 1,3-diaxial deshielding effect of the hydroxyl group on ring hydrogens studied from partially deuterated six-membered ring compounds. J. Pharm. Sci. 55 : 211 213, 1966

10) HAnson, J. R. : The nuclear magnetic resonance spectra of some gibberellin derivatives. J. Chem. Soc. $1965:$ 5036 5040, 1965

11) Tori, K. \& K. Anono : NMR studies on steroids. V. Steroidal sapogenins and their derivatives (in Japanese). Ann. Rept. Shionogi Res. Lab. $14: 136 \sim 155,1964$

12) Tori, K. \& E. Kondo : Structure determination of microbiologically hydroxylated $\Delta^{4}-3-$ oxo- $^{-}$ steroids by NMR spectroscopy and its applications. Steroids $4: 713 \sim 727,1964$

13) Minato, H. \& M. Ishikawa : Studies on sesquiterpenoids. Structure and absolute configuration of oplodiol. J. Chem. Soc. C : 423 427, 1967

14) Harris, D. R.; S. G. McGeachin \& H. H. Mills : The structure and stereochemistry of erythromycin A. Tetrahedron Letters 1965-11:679 685, 1965

15) Celmer, W. D. : Biogenetic, constitutional, and stereochemical unitary principles in macrolide antibiotics. Antimicr. Agents \& Chemoth.-1965: 144 156, 1966

Biogenesis of Antibiotic Substances, Ch. 10, p. 99, Z. VAneK and Z. Hostalek, ed. Academic Press, Inc., New York, N. Y., 1965; W. D. Celmer: Abstracts of 150 th Meeting, American Chemical Society. p. 10P, 1965

16) Bhacca, N. S. \& D. H. Williams : Application of NMR spectroscopy in organic chemistry. p. 63, Holden-Day, Inc., San Francisco, California, 1964

17) Karplus. M. : Contact electron-spin coupling of nuclear magnetic moments. J. Chem. Phys. $30: 11 \sim 15,1959$

Karplus, M. : Vicinal proton coupling in nuclear magnetic resonance. J. Am. Chem. Soc. $85: 2870 \sim 2871,1963$

18) Apsimon, J. W.; W. G. Craig, P. V. Demarco, D. W. Mathieson, A. K. G. Nasser, L. Saunders \& W. B. WALLEY : The anisotropies of the carbonyl group. Chemical Communications 754, 1966 